\title{
ECG Compression using the Three-Level Quantization and Wavelet Transform
}

\author{
Milad Azarbad \\ Faculty of Electrical and Computer Engineering \\ BABOL University of Technology
}

\author{
Ataollah Ebrahimzadeh \\ Faculty of Electrical and Computer Engineering \\ BABOL University of Technology
}

\begin{abstract}
The Electrocardiogram signals are a very valuable source of data for physicians in diagnosing heart abnormalities. In this paper, we present an efficient technique for compression of electrocardiogram (ECG) signals. A new thresholding method based on the three level of quantization is proposed for encoding samples using an Embedded Zero-tree Wavelet (EZW) and Huffman algorithms. The modified encoding algorithm allows an optimal data compression for a target bit rate and appeared superior to other wavelet-based ECG coders. Also, to improve the efficiency of the proposed method we propose to use different types of wavelet and compare their performances for compression of the ECG signals. Experimental results show that the proposed method has a good performance and less complexity for compression of ECG database from MIT-BIH database different types of wavelet transform.
\end{abstract}

\section{General Terms}

Electrocardiogram signal, ECG, Data Compression, Thresholding, Encoding Algorithms

\section{Keywords}

Discrete Wavelet Transform (DWT), EZW, Huffman Coding, Three-Level Quantization,

\section{INTRODUCTION}

The electrocardiogram is commonly needed because it is a noninvasive way to establish clinical diagnosis of heart diseases. The records have become widely used to extract some considered information from the heart signals. With increasing use of ECG in heart diagnosis, such as 24 monitoring or in ambulatory monitoring systems, the volume of ECG data that should be stored or transmitted, has greatly increased. Therefore we need to reduce the data volume to decrease storage cost or make ECG signal suitable and ready for transmission through common communication channels such as phone line or mobile channel. So, an effective data compression method is needed.

The main aim of any compression method is to accomplish maximum data reduction while preserving the significant signal morphology features upon reconstruction. Compression methods can be classified into three categories: 1) direct methods: These are time-domain Techniques; where the samples of the signal are directly handled to provide the compression. Coding by time-domain methods is based on the idea of extracting a subset of significant signal samples to represent the signal. Examples of the methods belonging to this group are Amplitude-Zone-Time Epoch Coding method (AZTEC) [1], Coordinate Reduction Time Encoding System (CORTES) [2]. The key to the successful algorithm is a good rule to determine the most significant samples.

2) Linear Transformation Methods: where the original samples are subjected to a transformation and the compression is performed in the new domain. Wavelet coefficients are encoded based on the characteristics that the coefficients are ordered in hierarchies [3-5]. This implies that many of the transform coefficients will have little energy and may be discarded. A variety of encoding methods, for instance vector quantization and linear prediction, are used directly to the wavelet coefficients [6-9].

3) Parametric Methods: More recently reported in the literature, are combinations of direct and transformation techniques methods, typical examples being beat codebook [10] and artificial neural network [11]. Transform compression using the WT is an efficient and flexible scheme [12]. In recent year many of the research studies have been concentrated on Discrete Wavelet Transform (DWT) coding. Many efficient algorithms have been used to encode the DWT coefficients. Examples include: Embedded Zero-tree Wavelet encoding [13], the Set Partitioning in Hierarchical Tree (SPIHT) [14] and the wavelet coding using Vector Quantization [15].

In this paper, a different thresholding method has been performed using the Three-Level Quantization and EZW \& Huffman encoding for a better compression. Figure1 shows the block diagram of the proposed method for ECG compression. For lossy compression techniques, the definition of the error criterion to appreciate the distortion information can lead to wrong diagnostics. The measurement of these distortions is a difficult problem and it is only partially solved for biomedical signals. In bio-signal compression, adopting the proper evaluation criteria is important. Most common figure used for compression performance evaluation is percentage root mean square difference (PRD), compression ratio (CR) [16-19]. In most ECG compression algorithms, the percentage root-meansquare difference (PRD) measure defined as:

$$
P R D=\sqrt{\frac{\sum_{i=1}^{N}[x(i)-\hat{x}(i)]^{2}}{\sum_{i=1}^{N}[x(i)]^{2}}} \times 100 \%
$$

Where $\mathrm{x}$ is the original signal, $\hat{x}$ is the reconstructed signal, and $\mathrm{N}$ is the length of the window over which the PRD is calculated. In this paper the correlation coefficient (CC) is used as a measure. It is described by:

$$
C C=\frac{\frac{1}{N} \sum_{i=1}^{N}\left(x_{i}-\bar{x}\right)\left(\hat{x}_{i}-\overline{\hat{x}}\right)}{\sqrt{\frac{1}{N} \sum_{i=1}^{N}\left(x_{i}-\bar{x}\right)^{2}} \sqrt{\frac{1}{N} \sum_{i=1}^{N}\left(\hat{x}_{i}-\overline{\hat{x}}\right)^{2}}}
$$

Where $\mathrm{x}$ is the original signal, $\hat{x}$ is the reconstructed signal, $\bar{x}$ is the average of original signal, $\overline{\hat{x}}$ is the average of reconstructed signal. It should be noted that this measure used to evaluate the similarity between two signals has the drawback of its global (average) nature. The compression ratio (CR) is defined as the ratio between the number of bits needed to represent the original and the compressed signal. The compression ratio is described by: 
$C R=\frac{n_{b c}}{n_{a c}}$

Where $n_{a c}$ is number of bits in the compressed signal duration and $n_{b c}$ is number of bits in original signal.

This paper is organized as follows. Section 2 describes the discrete wavelet transform (DWT). Section 3 presents the thresholding and the three-level quantization of the coefficients vector. Section 4 explains the encoding of the quantized coefficients using EZW without thresholding and Huffman algorithms. Section 5 shows the simulation results. Section 6 concludes the paper. Here, we have proposed an algorithm using wavelet transform and EZW encoding based on the three-level quantization to achieve a better performance. As shown in Figure 1 , the block diagram of the proposed method to compress ECG signals is illustrated in the following place.

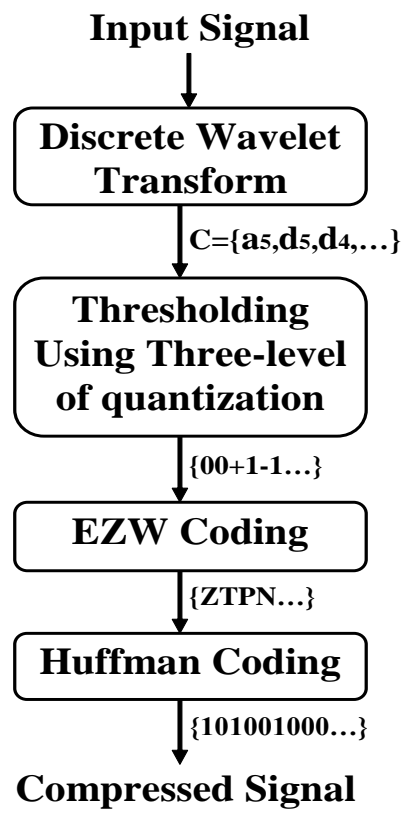

Figure 1. Block diagram of the proposed ECG compression method

\section{DISCRETE WAVELET TRANSFORM}

The discrete wavelet transform (DWT) is introduced as a novel method to analyze signals in both time and frequency domains, and therefore it is suitable for the analysis of time-varying non stationary signals such as ECG. The WT overcomes the fixed resolution analysis of the short time Fourier transform (STFT). This makes the wavelets an ideal tool for analyzing signals of a non-stationary nature. Their irregular shape lends them to analyzing signals with discontinuities or sharp changes, while their compactly supported nature enables temporal localization of signals' features. A mother wavelet $\psi(t)$ is a function of zero average:

$$
\int_{-\infty}^{+\infty} \psi(t) d t=0
$$

In discrete wavelet transform, two functions are used: wavelet function $\psi(t)$ and scaling function $\varphi(t)$. If we have a scaling function $\varphi(t)$, then the sequence of subspaces spanned by its scaling and translations:

$$
\begin{aligned}
& \varphi_{j, k}(t)=2^{j / 2} \varphi\left(2^{j} t-k\right) \\
& \varphi(t)=\sqrt{2} \sum_{n} h(n) \varphi(2 t-n)
\end{aligned}
$$

For mother wavelet we have: $\psi_{j, k}(t)=2^{j / 2} \psi\left(2^{j} t-k\right)$

$\psi_{j, k}(t)=\sqrt{2} \sum_{n} g(n) \varphi(2 t-n)$

For orthogonal basis we have:

$g(n)=(-1)^{n} h(-n+1)$

Where $h(n)$ is low pass filter and $g(n)$ is high pass filter. If we want to find the projection of a function $f(t)$ on this set of subspaces, it must be expressed in each subspace as a liner combination of expansion function of that subspace [20]:

$f(t)=\sum_{k=-\infty}^{\infty} c(k) \varphi_{k}(k)+\sum_{j=0}^{\infty} \sum_{k=-\infty}^{\infty} d(j, k) \psi_{j, k}(t)$

$\psi(t)$ is function of the discrete wavelet, the transform can be represented, as a tree of low a high pass filter, with each step transforming the output of the low pass filter. Figure 2 shows the wavelet decomposition tree, where the boxes represent linear convolution and circles represent down sampling by a factor of two (removal of every other sample). The original signal is successively decomposed into components of lower resolution, while the high frequency components are not analyzed any further. At each of the DWT algorithm, there are outputs: the scaling coefficients, $c_{n}^{j+1}$ and the wavelet coefficients, $d_{n}^{j+1}$ .These coefficients are given respectively, by:

$$
\begin{aligned}
& c^{j+1}(m)=\sum_{i=1}^{2 m} h(2 m-i) c^{j}(m) \\
& d^{j+1}(m)=\sum_{i=1}^{2 m} g(2 m-i) c^{j}(m)
\end{aligned}
$$

Here, $g$ and $h$ represent the low pass and high pass filters' transfer functions respectively. The output scaling coefficients are considered as the input samples to the next stage in the DWT algorithm [20-21]. The wavelet coefficients are described by:

$$
\begin{gathered}
d_{n}^{M}\left(n=0,1,2, \ldots, \frac{L}{2^{M}}-1\right) \\
d_{n}^{M-1}\left(n=0,1,2, \ldots, \frac{L}{2^{M-1}}-1\right) \\
\vdots \\
d_{n}^{1}\left(n=0,1,2, \ldots, \frac{L}{2}-1\right)
\end{gathered}
$$

$\mathrm{L}$ denotes the maximum number of scales that can be performed. It depends on the size of the data to be analyzed.

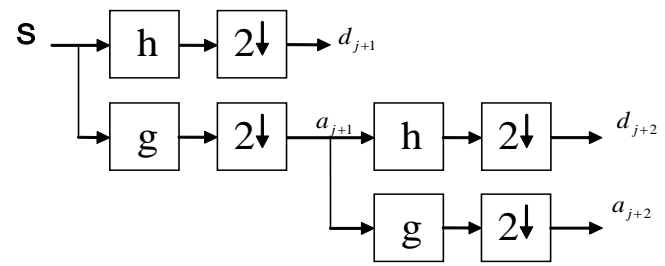

Figure 2. The Structure of Discrete Wavelet Transform

The initial decomposition produces two sets of data: a set of approximation coefficients and a set of detail coefficients. The $\mathbf{S}$ in the first row represents the entire signal, with no decomposition. The first stage represents the first level of decomposition. There, node $a_{j+1}$ shows the approximation coefficient and $d_{j+1}$ states the detail coefficients. This stage represents the first level of decomposition, where an approximation and detail are generated for the first level of approximation and an approximation and detail are generated for the first level detail in the second stage. In this paper, we used a discrete wavelet transform with 5 levels of 
decomposition ( $\mathrm{M}=5)$, the length of signal: 2048 samples $(\mathrm{n}=2048)$. All detail coefficients $\left\{d_{5}, d_{4}, d_{3}, d_{2}, d_{1}\right\}$ $(1 \leq \mathrm{M} \leq 5)$ and approximation coefficient $a_{5} \quad(\mathrm{M}=5)$ are assembled together in the coefficient vector (C): $C=\left[a_{5}, d_{5}, d_{4}, d_{3}, d_{2}, d_{1}\right]$

\subsection{Orthogonal Wavelets (dbN, symN)}

Let us recall that a multiresolution approximation is a nested sequence of linear space. The orthogonal complement $W_{j}$ of

$V_{j}$ in $V_{j-1}$ can be thus defined:

$V_{j-1}=V_{j} \oplus W_{j}$

Then there is a function $\psi$ such that the family $\psi_{j, n}(t)=2^{-j / 2} \psi\left(2^{-j} t-n\right), \mathrm{n}$ in $\mathrm{Z}$, is an orthonormal basis of $W_{j}$. The family $\psi_{j, n}, \mathrm{j}$ in $\mathrm{Z}$ and $\mathrm{n}$ in $\mathrm{Z}$, is an orthonormal basis of $\mathrm{L}^{2}$ and:

$L^{2}(R)=V_{j} \oplus_{j \in Z} W_{j}=V_{j} \oplus_{k \leq j} W_{k}$

$\psi$ is an orthogonal wavelet associated to the multi-resolution approximation [27]. A signal $\mathrm{f}$ in $\mathrm{L}^{2}$ can be decomposed as:

$f(t)=\sum_{j, n \in Z}<f, \psi_{j, n}>\psi_{j, n}(t)$

$=\sum_{n \in Z}<j, \varphi_{j, n}>\varphi_{j, n}(t)+\sum_{k \leq j, n \in Z}<f, \psi_{k, n}>\psi_{k, n}(t)$

$\varphi$ is an orthogonal scaling function of the multiresoution One can verify the other resolutions are generated by a suitable dilatation of these bases of translated atoms. Since the resolutions are embedded, there is necessarily a sequence of real number $h[n]$ such that:

$\frac{1}{\sqrt{2}} \varphi\left(\frac{t}{2}\right)=\sum_{n=-\infty}^{+\infty} h[n] \varphi(t-n)$

In this study, we have examined the symN and $\mathrm{dbN}$ wavelet families that include: Sym8, Sym7, Sym5, db3 and db2.

\subsection{Biorthogonal Wavelet (BiorN)}

Leave Biorthogonal wavelets are defined similarly to orthogonal wavelets, except that the starting point is biorthogonal multi-resolution approximations. The following decompositions are performed:

$V_{j-1}=V_{j} \oplus W_{j}$ with $W_{j} \subset\left(V_{j}^{+}\right)^{\perp}$

$V_{j-1}^{+}=V_{j}^{+} \oplus W_{j}^{+}$with $W_{j}^{+} \subset\left(V_{j}\right)^{\perp}$

Like in the orthogonal case, a signal in $\mathrm{L}$ can be written as:

$f(t)=\sum_{j, n \in Z}<f, \psi_{j, n}^{*}>\psi_{j, n}(t)=$

$=\sum_{n \in Z}<j, \varphi_{j, n}^{*}>\varphi_{j, n}(t)+\sum_{k \leq j, n \in Z}<f, \psi_{k, n}^{*}>\psi_{k, n}(t)$

$=\sum_{j, n \in Z}<f, \psi_{j, n}>\psi_{j, n}^{*}(t)$

$=\sum_{n \in Z}<j, \varphi_{j, n}>\varphi_{j, n}^{*}(t)+\sum_{k \leq j, n \in Z}<f, \psi_{k, n}>\psi_{k, n}^{*}(t)$

In this paper, we have tested the Bior wavelet families that include: Bior4.4, Bior3.3, Bior3.1 and Bior2.2 as the biorthogonal wavelets.

\section{THREE-LEVEL QUANTIZATION}

In this section, the quantization of the coefficient vector $(C)$ is described. Due to the quantization, perfect reconstruction is not possible, and reconstruction errors occur. The quantization is performed iteratively by a three-level quantizer. Given the input vector $\mathrm{C}$ and the threshold $\Theta_{i}$ of the $i^{\text {th }}$ iteration, $\Theta_{i}$ described by:

$\Theta_{i}=\left\{\begin{array}{l}\frac{1}{2} \cdot \max _{k}(\mid c[k]), \ldots \ldots(i=1) \\ \frac{1}{2} \cdot \Theta_{i-1}, \ldots \ldots \ldots \ldots \ldots . .(i>1)\end{array}\right.$

$\forall k \in 1,2, \ldots, N$

Where $\Theta_{i}$ is a threshold of the $i^{t h}$ iteration that is generated by the above equation for beginning of quantization. The coefficients of vector $(C)$ are quantized by the quantizer that is defined by equation (19). The quantized coefficients $d_{\Theta_{n}}[k]$ are described by:

$d_{\Theta_{i}}[k]=\left\{\begin{array}{cc}1, & \text { if }\left(c[k]-\sum_{n=1}^{i=1} d_{\Theta_{i}}[k] \cdot \Theta_{i}\right)>\Theta_{i} \\ -1, & \text { if }\left(c[k]-\sum_{n=1}^{i=1} d_{\Theta_{i}}[k] \cdot \Theta_{i}\right)<-\Theta_{i} \\ 0, & \text { else }\end{array}\right.$

$\forall k \in 1,2, \ldots, N$

In this stage, the input vector includes a set of approximation and detail coefficients that is created in the five levels of decomposition. Results of this step are the quantized coefficients vector (C) that is generated by the equation (19). The quantized coefficients that are named $d_{\Theta_{n}}[k]$ include exclusively three symbols $\{-1,0,1\}$. Where $d_{\Theta_{n}}[k]=0$ denotes the insignificant coefficients that is not very important for reconstruction of the original signals and $d_{\Theta_{n}}[k]= \pm 1$ the significant ones that are very effective to decrease error rate. The wavelet coefficient $\hat{c}[k]$ can be reconstructed by using the quantized coefficients and the initial threshold $\Theta_{1}$ :

$\hat{c}[k]=\Theta_{1} \sum_{n=1}^{i} d_{\Theta_{n}}[k] \cdot 2^{n-1}$

\section{EZW AND HUFFMAN ENCODING}

The EZW algorithm has two very interesting properties [22-2324]. The first is that the EZW algorithm creates a connection between the wavelet coefficients from different sub-bands. This is the reason why several quantized coefficients from different sub-bands can be encoded using only one symbol .The second property is that the import coefficients are encoded using the successive approximated technique, which puts the most important parts of the coefficients at the beginning of a bit stream. Therefore, the encoder can easily stop encoding procedure at any desired target rate.

In this section, the encoding of the quantized coefficients is performed at each iteration level of the quantization procedure. The main goal of the encoding algorithm is to find a connection between the quantized coefficients $d_{\Theta_{i}}$ [.] from different subband. Also we don't need to calculate the threshold again by $t h r=2^{[\log \mid \max (C)]}$ equation because of the thresholding of the coefficient vector (C) in the previous section. Therefore in this stage, we only need to encode the results of the previous step to receive a better performance.

The EZW algorithm use an alphabet which includes four symbols $\{P, N, T, Z\}$. Symbols $P$ and $N$ indicate the sign of a significant quantized coefficients, respectively for values of +1 and -1. A non-significant coefficients is encoded with the symbol $\{\mathrm{T}\}$ if it the root of a zero-tree where all of its coefficients are non-significant. A zero-tree and its members are encoded with only one symbol, namely with its root. The 
symbols $\{Z\}$ describes those quantized coefficient, which are zero and do not belong to a zero-tree. The results of this stage are an encoded coefficients vector $\mathrm{C}$ with four symbols $\{\mathrm{P}, \mathrm{N}$, $\mathrm{T}, \mathrm{Z}$.

In the next stage, these coefficients with the Variable-Length Coding (Huffman Coding) are encoded. In the Huffman encoding, a code with shorter length is replaced by symbols that have a small number and a code with longer length is substituted by symbols that their number is very large. We have considered the number of each symbol and $\mathrm{Z}, \mathrm{T}, \mathrm{P}$ and $\mathrm{N}$ have been replaced by 1, 01, 001 and 000 codes, respectively. Table 1 describes this procedure:

TABLE 1. ENCODING SYMBOLS IN THE HUFFMAN ALGORITHM

\begin{tabular}{cc}
\hline \hline Symbol & Code \\
\hline $\mathrm{Z}$ & 1 \\
$\mathrm{~T}$ & 01 \\
$\mathrm{P}$ & 001 \\
$\mathrm{~N}$ & 000 \\
\hline \hline
\end{tabular}

\section{SIMULATION RESULTS}

In this section, we have compared the result of several experiments of our method with other ECG coders. The proposed algorithm was tested and evaluated using actual data from MIT-BIH arrhythmia database. These ECG databases were sampled at $360 \mathrm{~Hz}$ with the Resolution of $11 \mathrm{bits} / \mathrm{sample}$. We have used Daubechies (db3, db2), Symlet (sym8, sym7, sym5) and Biorthogonal wavelets (Bior2.2, Bior3.1, Bior3.3, Bior2.6, Bior4.4) with five levels of decomposition. The following results have been obtained using the records number: 101, 103, 105, 115, 117, 118, 119, 201, 205, 213 and 219. To gain an optimum performance, 2048 samples and 3 types of wavelet with 5-level decompression have been used for compression of ECG signals. In order to validate the proposed compression algorithm and to compare it with other methods, 11 records consisting of the 2048 samples from the MIT-BIH Arrhythmia database have been used. The ECG signals were digitized through sampling at 360 (samples/s), quantized and encoded with 11 bits.

We have compared the performance of our encoder with some kinds of encoders in the literature, wavelet-based coders and direct ECG signal coders. The PRD and CR results in a similar record have been compared. Now, the effects of the iterations of the three-level quantization on the PRD, CR have been evaluated.

TABLE 2. A COMPRESSION OF DIFFERENT ENCODING ALGORITHM FOR RECORD 117

\begin{tabular}{|ccc|}
\hline Algorithms & PRD (\%) & CR (\%) \\
\hline JPEG2000 [25] & 1.03 & $10: 1$ \\
\hline Sec \& SPIHT [26] & 1.01 & $8: 1$ \\
\hline SPIHT \& VQ [27] & 1.45 & $8: 1$ \\
\hline SPIHT [28] & 1.8 & $8: 1$ \\
\hline Hilton [35] & 2.6 & $8: 1$ \\
\hline WT \& Huffman [11] & 3.2 & $9.4: 1$ \\
\hline
\end{tabular}

\begin{tabular}{|c|c|c|}
\hline Djohn [36] & 3.9 & $8: 1$ \\
\hline Wavelet Neural Network [33] & 2.74 & $7.6: 1$ \\
\hline Jianhua Chen [32] & 1.08 & $12: 1$ \\
\hline $\begin{array}{l}\text { the block-based discrete } \\
\text { cosine transform }(D C T)[34]\end{array}$ & 1.18 & $9.56: 1$ \\
\hline$R L E$ [29] & 2.915 & $5.8: 1$ \\
\hline ASCII [30] & 7.89 & $15.72: 1$ \\
\hline Benzid [9] & 3.51 & 12.6:1 \\
\hline $\begin{array}{l}\text { Dc Equalization and } \\
\text { Complexity Sorting [31] }\end{array}$ & 1.118 & 13.75:1 \\
\hline Proposed Technique & 0.97 & 13.92:1 \\
\hline
\end{tabular}

Table 2 shows the performance of the different algorithms in comparison with our simulated results. According to the table, there are some ECG compression methods in the literature, The Wavelet Neural Network, RLE, Benzid, Jianhua Chen, Hilton, SPIHT, SPIHT\&VQ, Sec\&SPIHT and WT\&Huffman methods have presented a wavelet and wavelet packet-based EZW encoder [7]. They have reported respectively the PRD values of $2.74 \%, 2.915 \%, 3.51,1.08,2.6 \%, 1.8 \%, 1.45 \%, 1.01 \%$ and 3.2 with CR lower than 13. Also by comparison with other coders, the PRD ranges of $1.18 \%, 1.03 \%$ and $3.9 \%$ in Table 2 are significantly higher (inferior) compared to our results and also, their CR values of $9.56 \%, 10 \%$ and $8 \%$ are noticeably lower (inferior) in comparison with our presented results. In ASCII [36] a combination of CR and PRD that has been received is so bad. In table 2, the best combination of CR and PRD values of the coder compared here which is considerably better than others is $13.75: 1 \%$ and $1.118 \%$ for the Dc Equalization and Complexity Sorting method [38]. The proposed compression algorithm in this paper obtain an excellent performance ( $\mathrm{PRD}=0.97 \%$ and $\mathrm{CR}=13.92: 1 \%$ ) that is extremely better than other coders.

Figure 3 shows the effects of the iterations of quantization on PRD. According to the Figure, as the numbers of iterations increase, the values of PRD can be improve more and in low number of iterations, the PRD values increase sharply and it would be worse than. Fig. 4 shows the effects of the iterations of quantization on CR. It can be found from the Figure 4 that the values of $\mathrm{CR}$ would be increased when the numbers of iteration become lower. In other words, by decreasing the numbers of iteration, the values of CR can be better and by increasing iterations, the $\mathrm{CR}$ values would be worse.

We show the results of the $9^{\text {th }}, 8^{\text {th }}, 7^{\text {th }}, 6^{\text {th }}$ and $5^{\text {th }}$ iterations in Tables 3, 4, 5, 6 and 7 for eleven records. In this study, several types of wavelets named: $\mathrm{db} 3, \mathrm{db} 2$, Bior4.4, Bior3.3, Bior3.1, Bior2.2, Sym8, Sym7 and Sym5 are examined. 


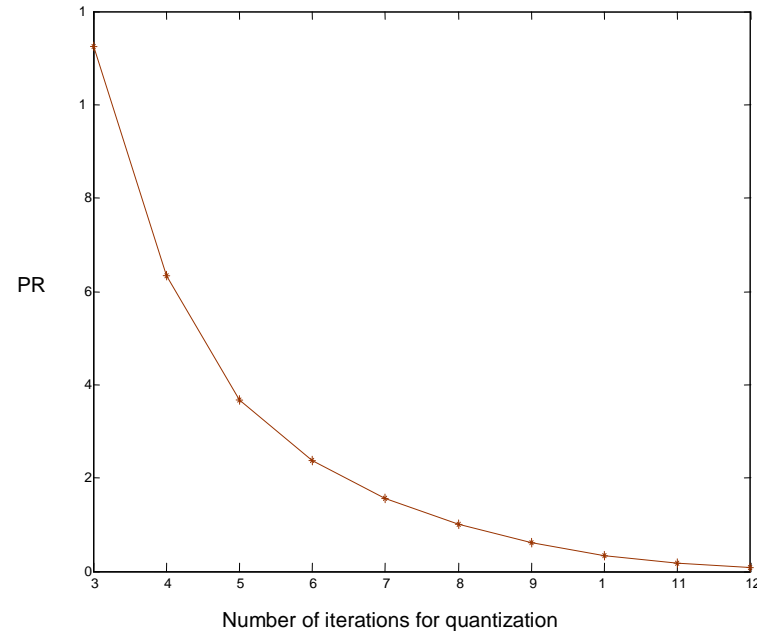

Figure 3. The effects of the iterations of quantization on PRD

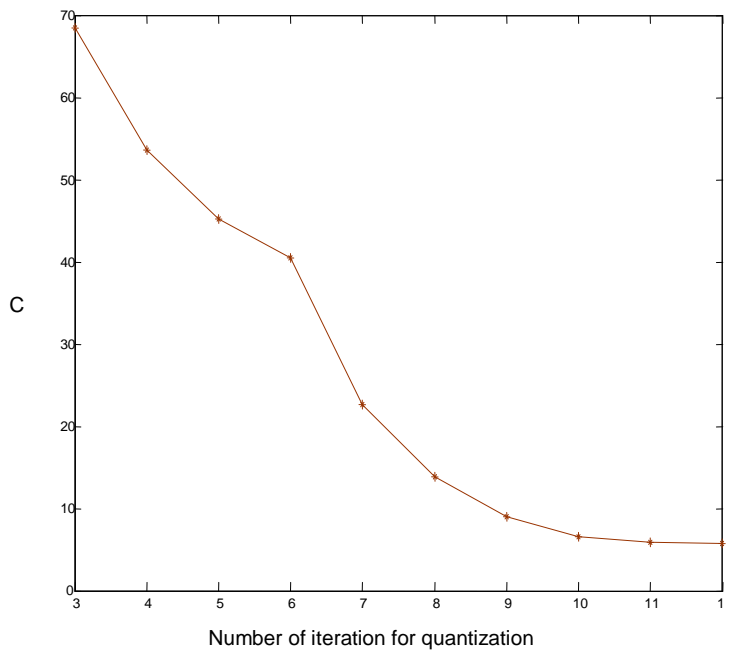

Figure 4. The effects of the iterations of quantization on CR

Table 3 shows the achieved results for compression of the $9^{\text {th }}$ iteration. The highest compression ratio $(\mathrm{CR}=15.3670 \%)$ was achieved using Bior3.1for record number 115. The lowest percent root-mean-square different $(\mathrm{PRD}=0.61511 \%)$ was achieved using sym8 for record no. 117. The correlation coefficients (CC) for all the records in 9th iteration are very excellent (CC>99.99\%). But it is noted that the performance of the compression algorithm is dependent on $\mathrm{CR}, \mathrm{PRD}$ and $\mathrm{CR}$ together. Because of it, the highest compression performance was achieved for record 219 using Bior3.1 with a CR of $13.9839 \%$, a PRD value of $0.71706 \%$ and $\mathrm{CC}=99.998 \%$. The fonts of the other better performances are boldface in Table 3 . (e.g. For record 219 using Sym8 wavelet, $\mathrm{CR}=11.92 \%$, $\mathrm{PRD}=0.75792 \%, \mathrm{CC}=99.997 \%$. For record 119 using Bior 3.1 wavelet, $\mathrm{CR}=13.2362 \%, \mathrm{PRD}=0.86724 \%, \mathrm{CC}=99.996 \%$. For record 117 using Sym8, $\mathrm{CR}=9.3014 \%, \mathrm{PRD}=0.61511 \%$, $\mathrm{CC}=99.998 \%$ )
Table 3. Results of the proposed algorithm in $9^{\text {th }}$ iteration of quantization using bior, $\mathrm{db}$ and sym wavelets for 11 records with $n=2048$ samples.

\begin{tabular}{|c|c|c|c|c|}
\hline Record & Wavelet & PRD & CR & $\overline{\mathrm{CC}}$ \\
\hline \multirow{3}{*}{101} & Bior3.1 & 1.0904 & 9.0802 & 99.994 \\
\hline & $\mathrm{db} 3$ & 0.79744 & 6.3710 & 99.997 \\
\hline & Sym8 & 0.77716 & 6.5204 & 99.997 \\
\hline \multirow{3}{*}{103} & Bior3.1 & 1.2863 & 13.579 & 99.992 \\
\hline & $\mathrm{db} 3$ & 0.9922 & 7.2788 & 99.995 \\
\hline & Sym8 & 0.92422 & 7.4057 & 99.996 \\
\hline \multirow{3}{*}{105} & Bior3.1 & 0.9803 & 9.3361 & 99.995 \\
\hline & $\mathrm{db} 3$ & 0.83652 & 6.4366 & 99.997 \\
\hline & Sym8 & 0.8343 & 6.8767 & 99.997 \\
\hline \multirow{3}{*}{115} & Bior3.1 & 1.0748 & 15.3670 & 99.995 \\
\hline & db3 & 0.77459 & 7.9915 & 99.997 \\
\hline & Sym8 & 0.66418 & 8.4851 & 99.998 \\
\hline \multirow{3}{*}{117} & Bior3.1 & 0.82503 & 11.976 & 99.997 \\
\hline & $\mathrm{db} 3$ & 0.65117 & 8.7658 & 99.998 \\
\hline & Sym8 & 0.61511 & 9.3014 & 99.998 \\
\hline \multirow{3}{*}{118} & Bior3.1 & 0.99121 & 11.5174 & 99.995 \\
\hline & $\mathrm{db} 3$ & 0.78613 & 8.5043 & 99.997 \\
\hline & Sym8 & 0.74643 & 9.4655 & 99.997 \\
\hline \multirow{3}{*}{119} & Bior3.1 & 0.86724 & 13.2362 & 99.996 \\
\hline & db3 & 0.95186 & 12.385 & 99.996 \\
\hline & Sym8 & 0.84927 & 12.564 & 99.997 \\
\hline \multirow{3}{*}{201} & Bior3.1 & 1.0062 & 8.7419 & 99.995 \\
\hline & $\mathrm{db} 3$ & 0.870 & 6.3459 & 99.996 \\
\hline & Sym8 & 0.8044 & 6.2456 & 99.996 \\
\hline \multirow{3}{*}{205} & Bior3.1 & 1.0027 & 12.2835 & 99.995 \\
\hline & $\mathrm{db} 3$ & 0.7189 & 7.3048 & 99.997 \\
\hline & Sym8 & 0.6457 & 7.4596 & 99.997 \\
\hline \multirow{3}{*}{213} & $\begin{array}{l}\text { Bior3.1 } \\
\end{array}$ & 0.97583 & 14.0888 & 99.996 \\
\hline & $\mathrm{db} 3$ & 1.076 & 9.398 & 99.995 \\
\hline & Sym8 & 0.8379 & 9.1436 & 99.997 \\
\hline \multirow{3}{*}{219} & Bior3.1 & 0.71706 & 13.9839 & 99.998 \\
\hline & $\mathrm{db} 3$ & 0.79073 & 10.591 & 99.997 \\
\hline & Sym8 & 0.75792 & 11.92 & 99.997 \\
\hline
\end{tabular}

It can be found from comparison of Table 3 and Table 4 that the values of $\mathrm{CR}$ and $\mathrm{PRD}$ decreased and the value of $\mathrm{CC}$ increased, when the numbers of iteration become higher. In other words, in the higher numbers of iteration, the PRD and $\mathrm{CC}$ performances become better values and the value of $\mathrm{CR}$ would be worse. Table 4 shows the achieved results for compression of the $8^{\text {th }}$ iteration. The highest compression ratio $(\mathrm{CR}=23.6639 \%)$ was achieved using Bior3.1for record no. 115 . The lowest percent root-mean-square different $(\mathrm{PRD}=0.97044 \%)$ was achieved using sym8 for record no. 117 The correlation coefficients (CC) for most of the records in 9th iteration are very excellent (CC>99.99\%). But generally, the performance of the compression algorithm is dependent on CR, PRD and CR together. The highest compression performance was achieved for record 219 using Bior3.1 wavelet with $\mathrm{CR}=18.3154 \%, \mathrm{PRD}=1.1508 \%$ and $\mathrm{CC}=99.994 \%$. And the other better performances are highlighted with boldface in Table 4. As seen from Table 4, some better performances are: record 219 using Bior3.1 wavelet with values of $\mathrm{CR}=11.18 .3154 \%, \mathrm{PRD}=1.508 \%$ and $\mathrm{CC}=99.997 \%$. Record 119 using db3 wavelet has the values of $\mathrm{CR}=21.293 \%$, $\mathrm{PRD}=1.5276 \%$ and $\mathrm{CC}=99.989 \%$. 
Table 4. Results of the proposed algorithm in $8^{\text {th }}$ iteration of quantization using bior, $\mathrm{db}$ and sym wavelets for 11 records with $n=2048$ samples

\begin{tabular}{|c|c|c|c|c|}
\hline Record & Wavelet & $\overline{\text { PRD }}$ & $\mathrm{CR}$ & $\mathrm{CC}$ \\
\hline \multirow{3}{*}{101} & Bior3.1 & 1.8531 & 12.7349 & 99.984 \\
\hline & $\mathrm{db} 3$ & 1.4949 & 8.3437 & 99.989 \\
\hline & Sym8 & 1.4288 & 8.4248 & 99.99 \\
\hline \multirow{3}{*}{103} & Bior3.1 & 2.0404 & 23.1056 & 99.981 \\
\hline & $\mathrm{db} 3$ & 1.7544 & 10.5419 & 99.985 \\
\hline & Sym8 & 1.5949 & 10.805 & 99.988 \\
\hline \multirow{3}{*}{105} & Bior3.1 & 1.6608 & 12.9994 & 99.987 \\
\hline & $\mathrm{db} 3$ & 1.5959 & 8.688 & 99.988 \\
\hline & Sym8 & 1.4987 & 9.0184 & 99.989 \\
\hline \multirow{3}{*}{115} & Bior3.1 & 1.7895 & 23.6639 & 99.986 \\
\hline & $\mathrm{db} 3$ & 1.3072 & 12.2768 & 99.992 \\
\hline & Sym8 & 1.0826 & 13.0220 & 99.994 \\
\hline \multirow{3}{*}{117} & Bior3.1 & 1.3217 & 15.8648 & 99.992 \\
\hline & $\mathrm{db} 3$ & 1.0714 & 13.474 & 99.994 \\
\hline & Sym8 & 0.97044 & 13.9234 & 99.995 \\
\hline \multirow{3}{*}{118} & Bior3.1 & 1.7186 & 15.7980 & 99.986 \\
\hline & $\mathrm{db} 3$ & 1.3365 & 11.2359 & 99.991 \\
\hline & Sym8 & 1.2392 & 11.6846 & 99.993 \\
\hline \multirow{3}{*}{119} & Bior3.1 & 1.4276 & 18.4052 & 99.991 \\
\hline & $\mathrm{db3}$ & 1.5276 & 21.293 & 99.989 \\
\hline & Sym8 & 1.3519 & 18.405 & 99.992 \\
\hline \multirow{3}{*}{201} & Bior3.1 & 1.668 & 10.3959 & 99.987 \\
\hline & $\mathrm{db} 3$ & 1.6522 & 7.855 & 99.986 \\
\hline & Sym8 & 1.5066 & 7.66 & 99.989 \\
\hline \multirow{3}{*}{205} & Bior3.1 & 1.6166 & 14.5342 & 99.988 \\
\hline & $\mathrm{db} 3$ & 1.2902 & 11.038 & 99.991 \\
\hline & Sym8 & 1.1059 & 12.041 & 99.994 \\
\hline \multirow{3}{*}{213} & Bior3.1 & 1.7402 & 18.0224 & 99.987 \\
\hline & $\mathrm{db} 3$ & 1.8256 & 12.6990 & 99.985 \\
\hline & Sym8 & 1.4005 & 12.2636 & 99.991 \\
\hline \multirow{3}{*}{219} & Bior3.1 & 1.1508 & 18.3154 & 99.994 \\
\hline & $\mathrm{db} 3$ & 1.2499 & 13.812 & 99.993 \\
\hline & Sym8 & 1.1804 & 13.695 & 99.994 \\
\hline
\end{tabular}

Table 5. Results of the proposed algorithm in $7^{\text {th }}$ iteration of quantization using bior, $\mathrm{db}$ and sym wavelets for 11 records with $n=2048$ samples.

\begin{tabular}{|c|c|c|c|c|}
\hline Record & Wavelet & PRD & CR & $\mathrm{CC}$ \\
\hline \multirow{3}{*}{101} & Bior3.1 & 2.9383 & 20.592 & 99.96 \\
\hline & $\mathrm{db} 3$ & 2.4508 & 14.3949 & 99.972 \\
\hline & Sym8 & 2.4005 & 14.1596 & 99.973 \\
\hline \multirow{3}{*}{103} & Bior3.1 & 3.1764 & 31.508 & 99.958 \\
\hline & db3 & 2.8022 & 23.7137 & 99.964 \\
\hline & Sym8 & 2.46 & 23.369 & 99.973 \\
\hline \multirow{3}{*}{105} & $\begin{array}{l}\text { Bior3.1 } \\
\end{array}$ & 2.7537 & 23.011 & 99.965 \\
\hline & db3 & 2.6366 & 15.16 & 99.967 \\
\hline & Sym8 & 2.4623 & 14.054 & 99.972 \\
\hline \multirow{3}{*}{115} & Bior3.1 & 2.9269 & 38.708 & 99.965 \\
\hline & $\mathrm{db} 3$ & 2.0547 & 20.8207 & 99.981 \\
\hline & Sym8 & 1.6648 & 17.0667 & 99.987 \\
\hline \multirow{3}{*}{117} & Bior3.1 & 2.1866 & 24.702 & 99.978 \\
\hline & db3 & 1.6835 & 20.8400 & 99.987 \\
\hline & Sym8 & 1.5128 & 20.5173 & 99.99 \\
\hline \multirow{3}{*}{118} & Bior3.1 & 2.8922 & 20.295 & 99.962 \\
\hline & $\mathrm{db} 3$ & 2.2309 & 15.9096 & 99.977 \\
\hline & Sym8 & 2.116 & 16.7744 & 99.98 \\
\hline \multirow{3}{*}{119} & Bior3.1 & 2.3023 & 29.068 & 99.977 \\
\hline & $\mathrm{db3}$ & 2.3733 & 29.526 & 99.976 \\
\hline & Sym8 & 2.1324 & 28.373 & 99.981 \\
\hline \multirow{3}{*}{201} & Bior3.1 & 2.8736 & 17.015 & 99.962 \\
\hline & $\mathrm{db} 3$ & 2.8425 & 11.642 & 99.962 \\
\hline & Sym8 & 2.5968 & 10.723 & 99.969 \\
\hline \multirow{3}{*}{205} & Bior3.1 & 2.718 & 23.345 & 99.967 \\
\hline & $\mathrm{db} 3$ & 2.0757 & 14.4410 & 99.98 \\
\hline & Sym8 & 1.6757 & 13.0521 & 99.987 \\
\hline \multirow{3}{*}{213} & Bior3.1 & 2.9586 & 29.0684 & 99.963 \\
\hline & $\mathrm{db} 3$ & 3.0349 & 17.6138 & 99.960 \\
\hline & Sym8 & 2.3647 & 16.9129 & 99.976 \\
\hline \multirow{3}{*}{219} & Bior3.1 & 1.8968 & 27.077 & 99.985 \\
\hline & $\mathrm{db} 3$ & 2.0768 & 20.574 & 99.981 \\
\hline & Sym8 & 1.9614 & 23.273 & 99.983 \\
\hline
\end{tabular}

Table 5 shows the achieved results for compression of the $7^{\text {th }}$ iteration. The best compression ratio $(\mathrm{CR}=38.708 \%)$ was achieved using Bior3.1for record no. 115. The lowest percent root-mean-square different $(\mathrm{PRD}=1.5128 \%)$ was achieved using sym8 for record no. 117. The highest correlation coefficient (CC) was obtained using sym8 wavelet for record number 117. But the performance of the compression is dependent on CR, PRD and CR. With this explanation, the highest compression performance was achieved for record 219 using Bior3.1 wavelet with $\mathrm{CR}=27.077 \%, \mathrm{PRD}=1.8968 \%$ and $\mathrm{CC}=99.985 \%$. It can be found from the table, some better performances are: record 115 using Bior3.1 wavelet with $\mathrm{CR}=38.708 \%, \mathrm{PRD}=2.9269 \%, \mathrm{CC}=99.965 \%$. Record 117 using sym8 wavelet with $\mathrm{CR}=20.5173 \%, \quad \mathrm{PRD}=1.5128 \%$, $\mathrm{CC}=99.99 \%$. Record 219 using Bior3.1 wavelet with the values of $\mathrm{CR}=27.077 \%, \mathrm{PRD}=1.8968 \%, \mathrm{CC}=99.985 \%$.

Table 6 and 7 show the simulation results of the proposed algorithm for $6^{\text {th }}$ and $5^{\text {th }}$ iterations. In these iterations, the values of CR and PRD are higher and the value of CC is lower. On the other hands, in the $6^{\text {th }}$ and $5^{\text {th }}$ numbers of iteration, the CR performance become better values and the values of PRD and $\mathrm{CC}$ would be worse. For iterations lower than 5, the compression ratio (CR) was achieved extremely high (the high $\mathrm{CR}$ is our favorite) but the percent root-mean-square different (PRD) that is a very important factor, was inferior (the value of PRD become high too whereas the low PRD is our preferable). And also for iterations higher than 9, the percent root-meansquare different (PRD) was obtained extremely low (the lower PRD is our admirable) but in these iterations, the compression ratio $(\mathrm{CR})$ was achieved lower whereas the low $\mathrm{CR}$ is inferior. Because of it, we show the simulation results from $5^{\text {th }}$ to $9^{\text {th }}$ iteration.

Table 6. Results of the proposed algorithm in $6^{\text {th }}$ iteration of quantization using bior, $\mathrm{db}$ and sym wavelets for 11 records with $\mathbf{n}=\mathbf{2 0 4 8}$ samples.

\begin{tabular}{|c|c|c|c|c|}
\hline Record & Wavelet & PRD & $\mathrm{CR}$ & $\mathrm{CC}$ \\
\hline \multirow{3}{*}{101} & Bior3.1 & 4.6081 & 33.775 & 99.908 \\
\hline & db3 & 3.6798 & 28.3371 & 99.939 \\
\hline & Sym8 & 3.5737 & 23.5402 & 99.944 \\
\hline \multirow{3}{*}{103} & $\begin{array}{l}\text { Bior3.1 } \\
\end{array}$ & 5.3956 & 45.056 & 99.889 \\
\hline & $\mathrm{db} 3$ & 4.0371 & 29.2952 & 99.932 \\
\hline & Sym8 & 3.597 & 25.484 & 99.95 \\
\hline \multirow{3}{*}{105} & $\begin{array}{l}\text { Bior3.1 } \\
\end{array}$ & 4.2107 & 38.509 & 99.925 \\
\hline & $\mathrm{db} 3$ & 3.9489 & 21.435 & 99.931 \\
\hline & Sym8 & 3.8968 & 22.825 & 99.935 \\
\hline \multirow{3}{*}{115} & Bior3.1 & 4.666 & 48.657 & 99.923 \\
\hline & $\mathrm{db} 3$ & 3.1341 & 33.3748 & 99.959 \\
\hline & Sym8 & 2.7054 & 27.676 & 99.969 \\
\hline \multirow{3}{*}{117} & Bior3.1 & 3.5025 & 46.739 & 99.948 \\
\hline & $\mathrm{db3}$ & 2.5686 & 34.2892 & 99.971 \\
\hline & Sym8 & 2.3483 & 34.1851 & 99.976 \\
\hline \multirow{3}{*}{118} & Bior3.1 & 4.8978 & 32.649 & 99.896 \\
\hline & db3 & 3.6659 & 21.9785 & 99.938 \\
\hline & Sym8 & 3.4013 & 20.9563 & 99.949 \\
\hline \multirow{3}{*}{119} & Bior3.1 & 3.8009 & 42.187 & 99.942 \\
\hline & db3 & 3.9123 & 35.145 & 99.939 \\
\hline & Sym8 & 3.4618 & 34.618 & 99.951 \\
\hline \multirow{3}{*}{201} & Bior3.1 & 4.5205 & 28.48 & 99.911 \\
\hline & $\mathrm{db} 3$ & 4.4088 & 21.851 & 99.915 \\
\hline & Sym8 & 4.1462 & 18.868 & 99.923 \\
\hline \multirow{3}{*}{205} & Bior3.1 & 4.4083 & 37.547 & 99.917 \\
\hline & $\mathrm{db} 3$ & 3.3845 & 26.5035 & 99.948 \\
\hline & Sym8 & 2.9333 & 21.1332 & 99.963 \\
\hline \multirow{3}{*}{213} & Bior3.1 & 4.8451 & 34.765 & 99.906 \\
\hline & $\mathrm{db} 3$ & 5.0816 & 22.3714 & 99.893 \\
\hline & Sym8 & 3.946 & 20.8786 & 99.935 \\
\hline \multirow{3}{*}{219} & Bior3.1 & 3.2694 & 40.085 & 99.96 \\
\hline & $\mathrm{db} 3$ & 3.378 & 29.031 & 99.953 \\
\hline & Sym8 & 3.1351 & 26.755 & 99.96 \\
\hline
\end{tabular}


Table 7. Results of the proposed algorithm in $5^{\text {th }}$ iteration of quantization using bior, $\mathrm{db}$ and sym wavelets for 11 records with $n=2048$ samples.

\begin{tabular}{|c|c|c|c|c|}
\hline Record & Wavelet & PRD & $\mathrm{CR}$ & $\mathrm{CC}$ \\
\hline \multirow{3}{*}{101} & Bior3.1 & 7.1957 & 48.974 & 99.802 \\
\hline & $\mathrm{db} 3$ & 5.4815 & 33.574 & 99.879 \\
\hline & Sym8 & 5.4879 & 29.3716 & 99.883 \\
\hline \multirow{3}{*}{103} & Bior3.1 & 9.2081 & 52.883 & 99.704 \\
\hline & $\mathrm{db} 3$ & 6.6052 & 32.1829 & 99.839 \\
\hline & Sym8 & 6.0897 & 32.602 & 99.869 \\
\hline \multirow{3}{*}{105} & Bior3.1 & 6.433 & 45.976 & 99.841 \\
\hline & $\mathrm{db} 3$ & 6.4408 & 36.75 & 99.824 \\
\hline & Sym8 & 6.216 & 33.474 & 99.848 \\
\hline \multirow{3}{*}{115} & Bior3.1 & 8.0969 & 59.441 & 99.783 \\
\hline & $\mathrm{db3}$ & 4.9235 & 42.1873 & 99.908 \\
\hline & Sym8 & 4.3565 & 39.72 & 99.927 \\
\hline \multirow{3}{*}{117} & Bior3.1 & 5.3753 & 53.007 & 99.902 \\
\hline & db3 & 4.1879 & 45.8819 & 99.931 \\
\hline & Sym8 & 3.8068 & 42.1873 & 99.951 \\
\hline \multirow{3}{*}{118} & Bior3.1 & 7.7908 & 50.398 & 99.759 \\
\hline & $\mathrm{db} 3$ & 5.8654 & 42.506 & 99.849 \\
\hline & Sym8 & 5.672 & 30.484 & 99.863 \\
\hline \multirow{3}{*}{119} & Bior3.1 & 6.3292 & 53.384 & 99.848 \\
\hline & $\mathrm{db} 3$ & 6.9183 & 47.932 & 99.817 \\
\hline & Sym8 & 5.9209 & 38.444 & 99.877 \\
\hline \multirow{3}{*}{201} & Bior3.1 & 7.0242 & 42.506 & 99.809 \\
\hline & $\mathrm{db} 3$ & 6.5277 & 31.508 & 99.829 \\
\hline & Sym8 & 6.3807 & 27.241 & 99.83 \\
\hline \multirow{3}{*}{205} & Bior3.1 & 7.1405 & 48.868 & 99.825 \\
\hline & $\mathrm{db} 3$ & 5.1001 & 33.9788 & 99.892 \\
\hline & Sym8 & 4.7871 & 30.8603 & 99.908 \\
\hline \multirow{3}{*}{213} & Bior3.1 & 8.3895 & 42.3459 & 99.731 \\
\hline & $\mathrm{db} 3$ & 8.7010 & 31.0303 & 99.697 \\
\hline & Sym8 & 6.8939 & 26.8831 & 99.815 \\
\hline \multirow{3}{*}{219} & Bior3.1 & 5.5204 & 52.759 & 99.898 \\
\hline & $\mathrm{db} 3$ & 5.6762 & 37.36 & 99.874 \\
\hline & Sym8 & 5.5653 & 31.289 & 99.886 \\
\hline
\end{tabular}

Table 8. A comparison of the average of PRD and CR based on the different wavelets and iterations of quantization

\begin{tabular}{|c|ccc|}
\hline Iteration & Wavelet & PRD (\%) & CR (\%) \\
\hline \multirow{2}{*}{$9^{\text {th }}$} & Bior3.1 & 0.983370 & 12.108180 \\
& db3 & 0.840505 & 8.306609 \\
& Sym8 & 0.768781 & 8.671600 \\
$\mathbf{8}^{\text {th }}$ & Bior3.1 & 1.635209 & 16.712700 \\
& db3 & 1.464164 & 11.932481 \\
& Sym8 & 1.305449 & 11.903890 \\
$7^{\text {th }}$ & Bior3.1 & 2.693036 & 25.853581 \\
& db3 & 2.387445 & 18.603245 \\
& Sym8 & 2.122491 & 18.025000 \\
$6^{\text {th }}$ & Bior3.1 & 4.374991 & 38.949909 \\
& db3 & 3.745418 & 27.601063 \\
& Sym8 & 3.376809 & 25.174490 \\
$5^{\text {th }}$ & Bior3.1 & 7.136664 & 50.049263 \\
& db3 & 6.038873 & 37.717381 \\
& Sym8 & 5.561527 & 32.959663 \\
\hline
\end{tabular}

Table 8 shows the average values of the performance accuracy at $9^{\text {th }}, 8^{\text {th }}, 7^{\text {th }}, 6^{\text {th }}$ and $5^{\text {th }}$ iterations for all the eleven records. Because the correlation coefficients (CC) for all the proposed records in all iterations are very excellent (CC>99\%), we have only calculated the average values of the PRD and CR for Bior3.1, db3 and Sym8 wavelets. As expected, the PRD is generally low and the compression ratio (CR) is achieved low at higher iterations and for lower iterations, the PRD and CR values are achieved higher. It can be seen from the Table8, The best compression ratio ( $\mathrm{CR}=50.17449 \%)$ was obtained using Bior3.1 and the lowest percent root-mean-square different was achieved ( $\mathrm{PRD}=0.768781 \%$ ) using sym8 wavelet for all the considered records. But as we mentioned before, the best performance depends on both $\mathrm{CR}$ and PRD. Therefore according to the values, the Bior 3.1 and sym 8 are achieved the best performances. The lower PRDs are achieved by sym 8 wavelet and the higher CRs are achieved by Bior3.1 for all the considered iterations.

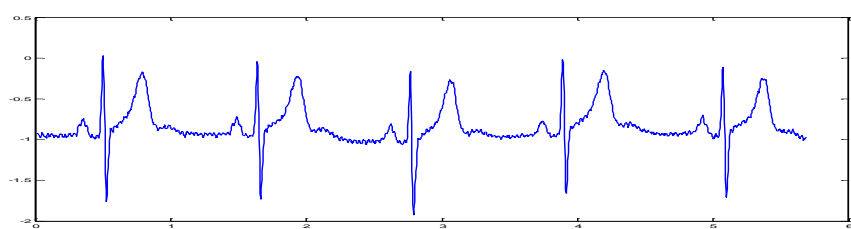

(a)

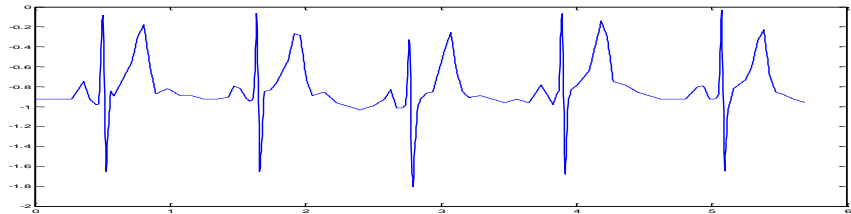

(b)

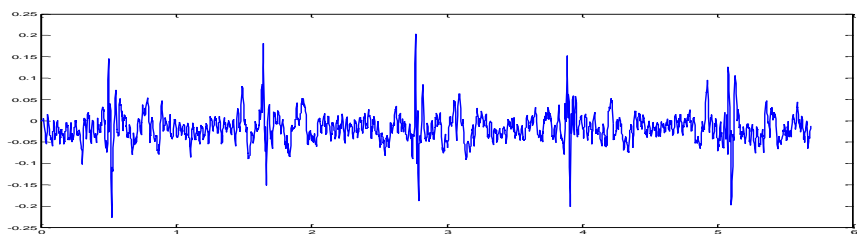

(c)

Figure 5. (a) Original signal, (b) Reconstructed signal, (c) Error signal.

ECG compression using Bior2.2 wavelet and 2048 samples of signal and $5^{\text {th }}$ iteration of quantization for record no. 117 from MIT-BIH database $(\mathrm{CR}=59.9149, \mathrm{PRD}=4.2883, \mathrm{CC}=99.928)$

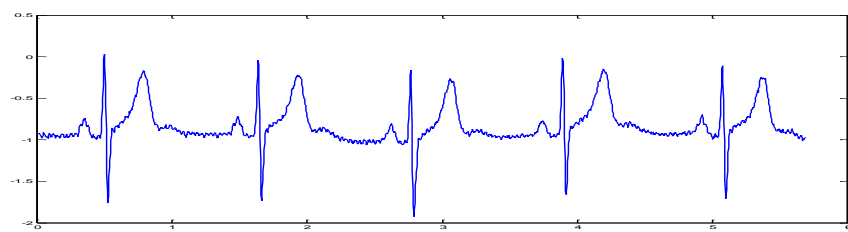

(a)

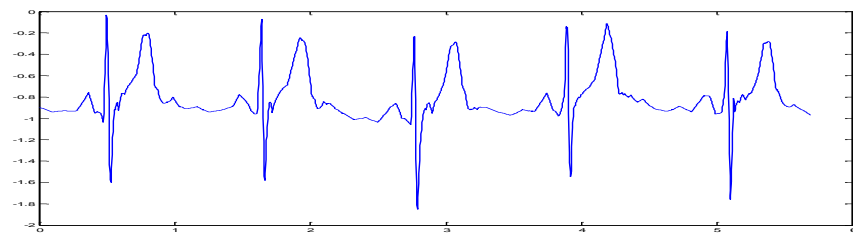

(b)

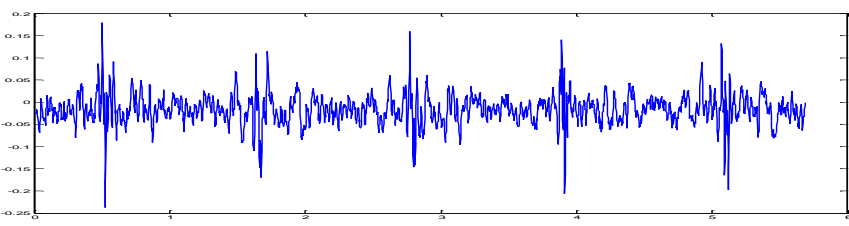

(c)

Figure 6. (a) Original signal, (b) Reconstructed signal, (c) Error signal.

ECG compression using db3 wavelet and 2048 samples of signal and $5^{\text {th }}$ iteration of quantization for record no. 117 from MIT-BIH database $(\mathrm{CR}=45.8819, \mathrm{PRD}=4.1879, \mathrm{CC}=99.931)$ 


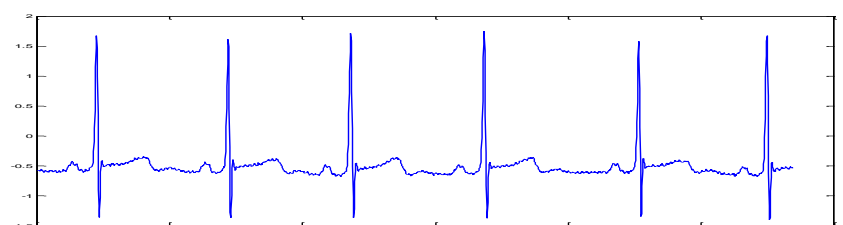

(a)

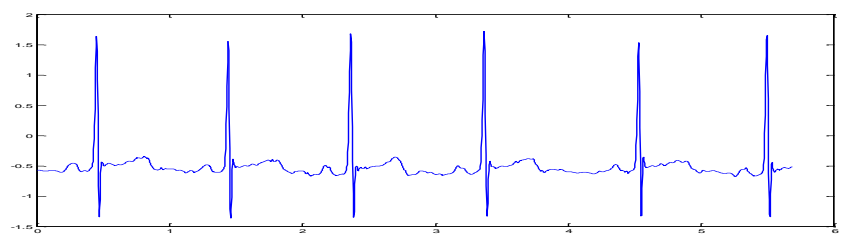

(b)

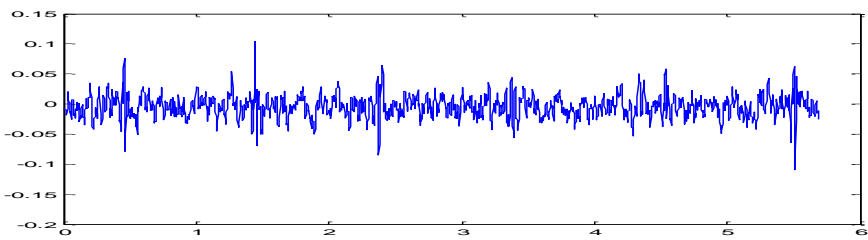

(c)

Figure 7. (a) Original signal, (b) Reconstructed signal, (c) Error signal.

ECG compression using Bior3.1 wavelet and 2048 samples of signal and $8^{\text {th }}$ iteration of quantization for record no. 115 from MIT-BIH database $(\mathrm{CR}=23.6639, \mathrm{PRD}=1.7895, \mathrm{CC}=99.986)$

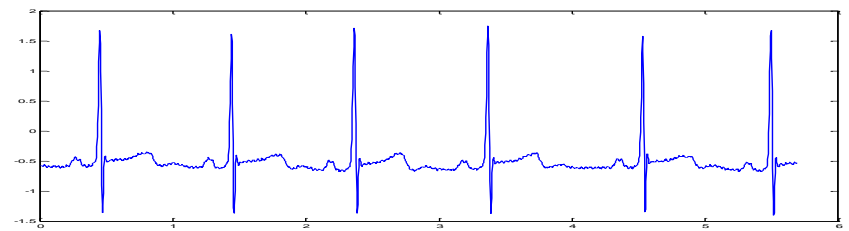

(a)

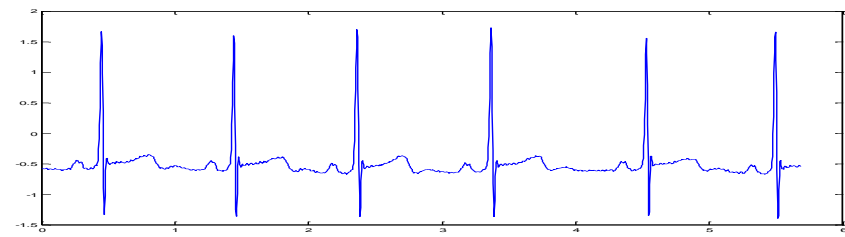

(b)

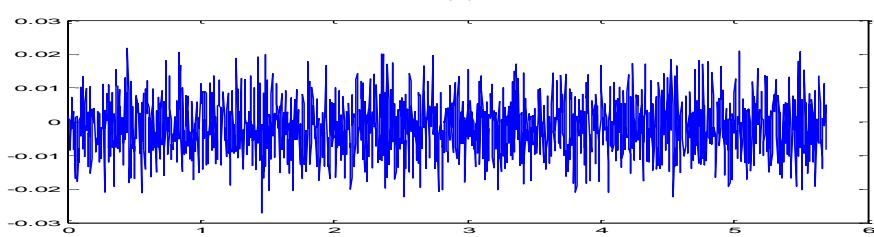

(c)

Figure 8. (a) Original signal, (b) Reconstructed signal, (c) Error signal.

ECG compression using db3 wavelet and 2048 samples of signal and $8^{\text {th }}$ iteration of quantization for record no. 115 from MIT-BIH database $(C R=12.5925, P R D=1.1309, C C=99.994)$

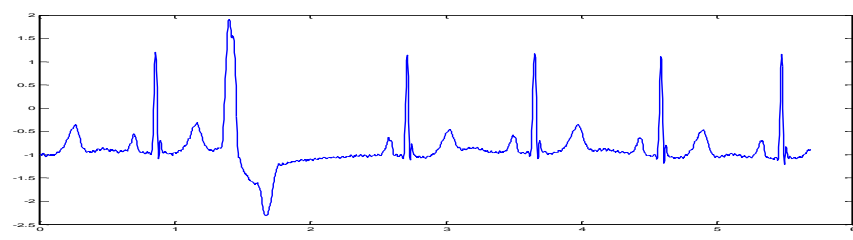

(a)

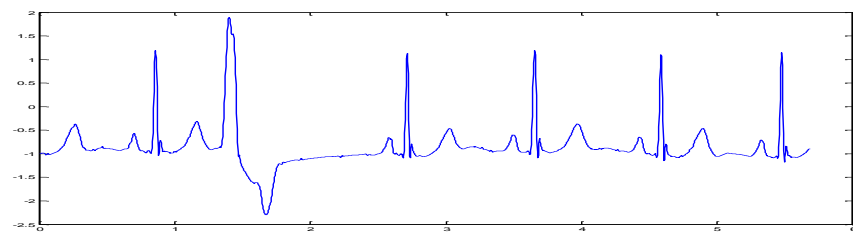

(b)

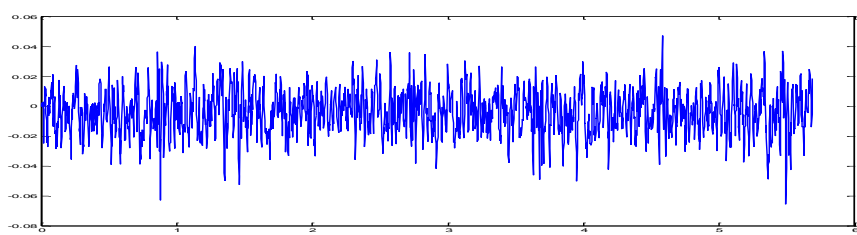

(c)

Figure 9. (a) Original signal, (b) Reconstructed signal, (c) Error signal.

ECG compression using Bior4.4 wavelet and 2048 samples of signal and $8^{\text {th }}$ iteration of quantization for record no. 119 from MIT-BIH database $(\mathrm{CR}=22.2170, \mathrm{PRD}=1.4032, \mathrm{CC}=99.991)$

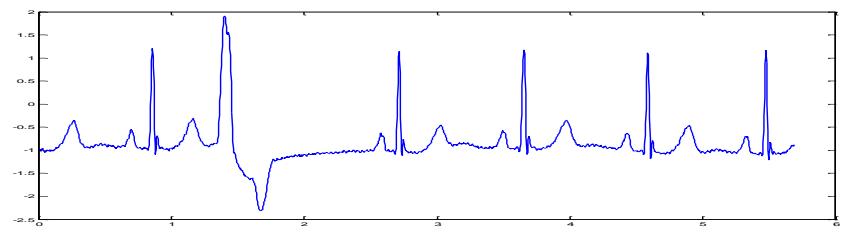

(a)

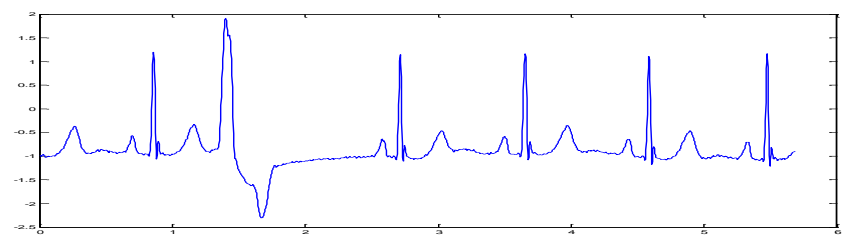

(b)

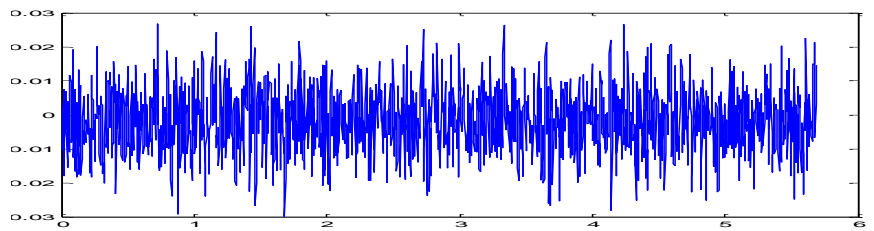

(c)

Figure 10. (a) Original signal, (b) Reconstructed signal, (c) Error signal.

ECG compression using Sym7 wavelet and 2048 samples of signal and $9^{\text {th }}$ iteration of quantization for record no. 119 from MIT-BIH database $(\mathrm{CR}=12.364, \mathrm{PRD}=0.82527, \mathrm{CC}=99.997)$ 


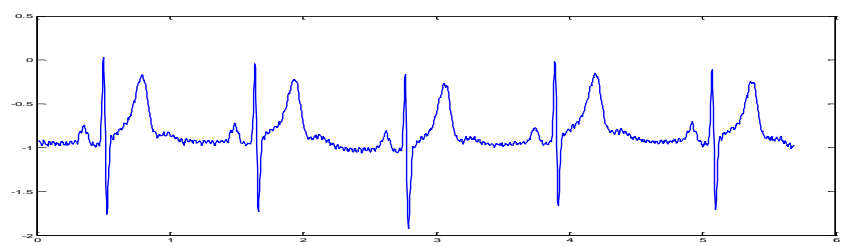

(a)

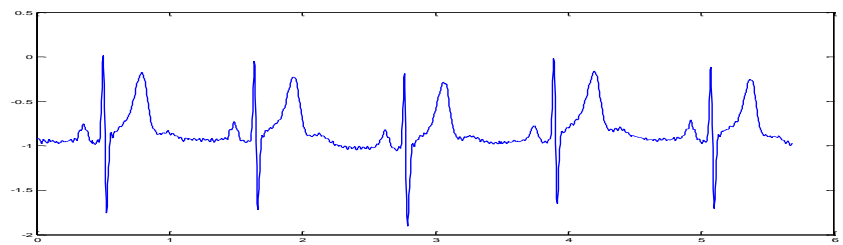

(b)

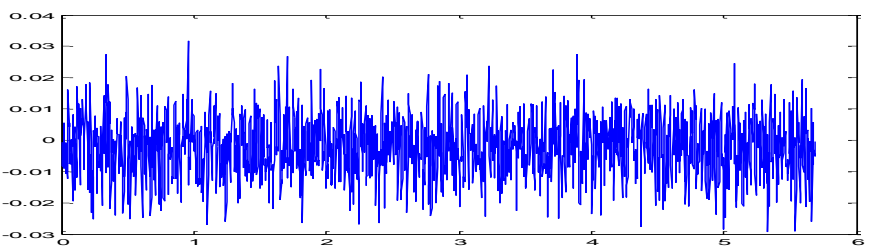

(c)

Figure 11. (a) Original signal, (b) Reconstructed signal, (c) Error signal.

ECG compression using sym8 wavelet and 2048 samples of signal and $8^{\text {th }}$ iteration of quantization for record no. 119 from MIT-BIH database $(\mathrm{CR}=13.923, \mathrm{PRD}=0.97044, \mathrm{CC}=99.995)$

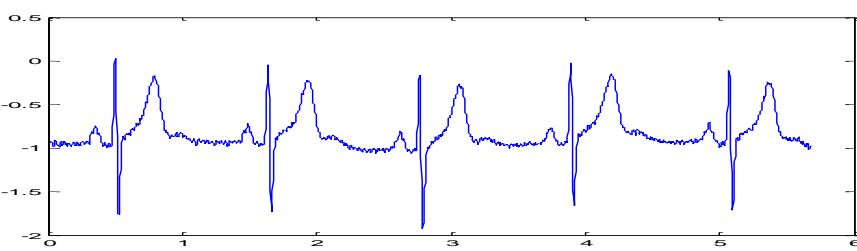

(a)

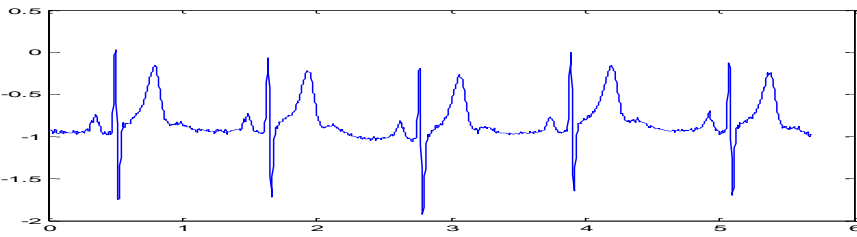

(b)

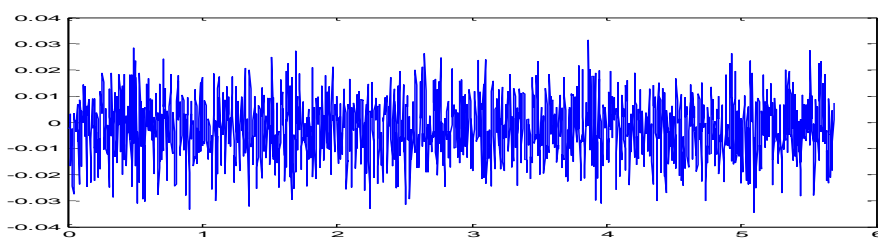

(c)

Figure 12. (a) Original signal, (b) Reconstructed signal, (c) Error signal.

ECG compression using db2 wavelet and 2048 samples of signal and $8^{\text {th }}$ iteration of quantization for record no. 117 from MIT-BIH database $(\mathrm{CR}=13.037, \mathrm{PRD}=1.2312, \mathrm{CC}=99.993)$

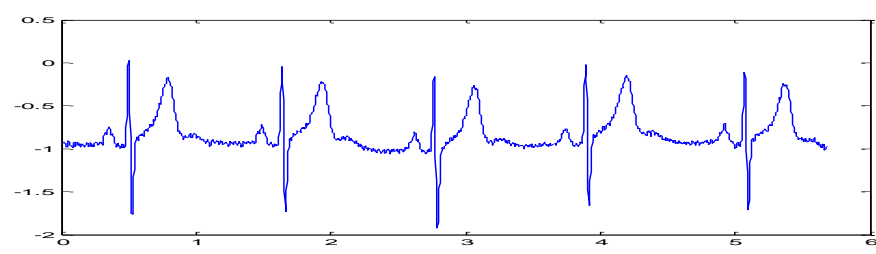

(a)

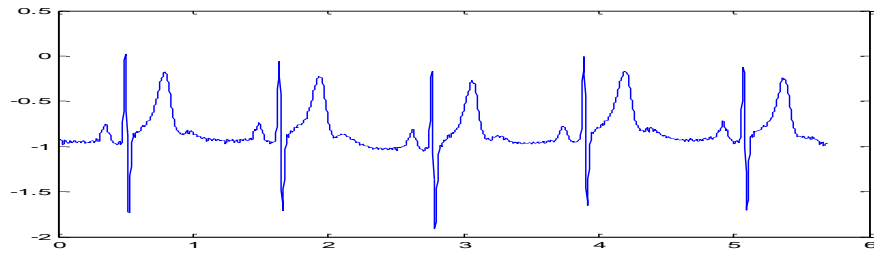

(b)

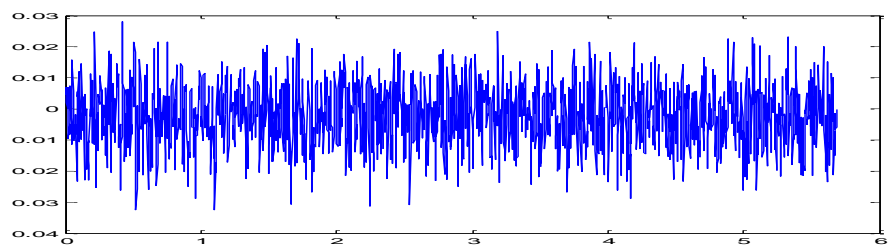

(c)

Figure 13. (a) Original signal, (b) Reconstructed signal, (c) Error signal.

ECG compression using sym5 wavelet and 2048 samples of signal and $8^{\text {th }}$ iteration of quantization for record no. 117 from MIT-BIH database $(\mathrm{CR}=13.346, \mathrm{PRD}=1.0594, \mathrm{CC}=99.998)$

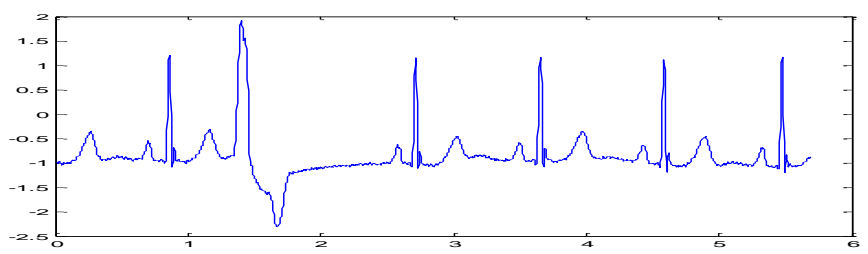

(a)

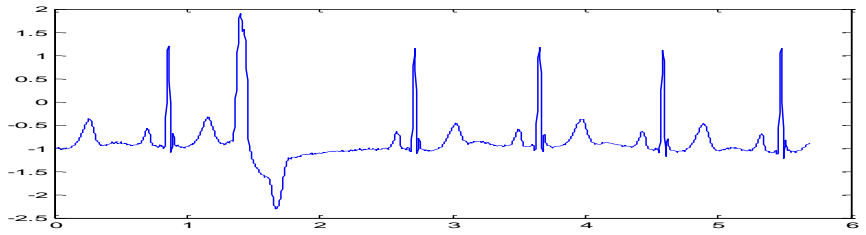

(b)

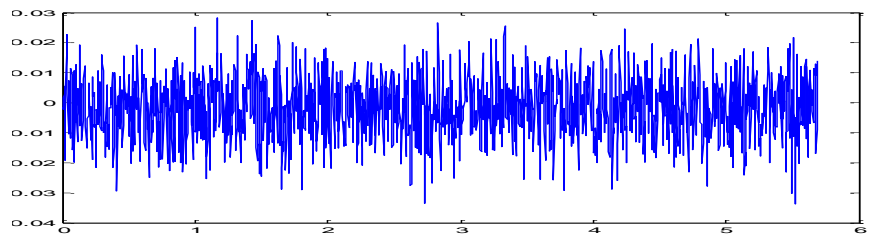

(c)

Figure14. (a) Original signal, (b) Reconstructed signal, (c) Error signal.

ECG compression using db2 wavelet and 2048 samples of signal and $8^{\text {th }}$ iteration of quantization for record no. 117 from MIT-BIH database $(\mathrm{CR}=13.037, \mathrm{PRD}=1.2312, \mathrm{CC}=99.993)$ 


\section{CONCLUSION}

The proposed algorithm for compression of ECG signals using wavelet transforms and EZW\& Huffman encoding based on the three-level quantization is described in this Paper. The algorithm is examined for compression of 11 records of ECG signal from the MIT-BIH database. The experimental results indicate that the presented wavelets in this coder have high performance. The some of biorthogonal wavelets have a performance better than the orthogonal wavelets. In this paper, combination of three-level quantization and EZW together for thresholding and encoding has been used. After selecting threshold, the three-level quantization has been continued from $1^{\text {th }}$ level to $12^{\text {th }}$ level of iteration. In low iterations, the values of $\mathrm{CR}$ and PRD are higher and the value of CC is lower. On the other hands, in the lower numbers of iteration, the compression ratio (CR) is achieved extremely high (CR become better values) but the percent root-mean-square different (PRD) that is a very important factor, is inferior (the value of PRD become high too whereas the low PRD is our favorite). And also for high iterations, the PRD is obtained extremely low (the lower PRD is our admirable) but in these iterations, the CR values are achieved lower whereas the low CR is inferior. Consequently, it seems reasonable to conclude that the best simulation results are achieved for $5^{\text {th }}$ to $9^{\text {th }}$ iterations. The three kinds of wavelet were tested to gain the acceptable results named: $\mathrm{db}$, bior and sym.

The different results have gained for each wavelet and record number. Among all wavelets, in higher iterations, sym8 and some of biorthogonal wavelets (bior2.2, bior3.3, bior3.1 and bior4.4) achieved better results. Also, we have concluded that if high compression rates need, we should continue iterations of quantization for lower than $4^{\text {th }}$ level. Consequently, if we want to decrease the PRD value, the iterations of the three-level quantizer can be continued to high levels. Generally, for values of CR>50 and 3.5<PRD, the three-level quantization should be continued to $4^{\text {th }}$ or $5^{\text {th }}$ level of iteration. If a ratio around $24<\mathrm{CR}<50$ and $1.5<\mathrm{PRD}<3.5$ is our favorite, we should repeat the three-level quantization to $6^{\text {th }}$ or $7^{\text {th }}$ iteration. For $6<\mathrm{CR}<24$ and $0.6<\mathrm{PRD}<1.7$, it should be quantized to $8^{\text {th }}$ or $9^{\text {th }}$ iteration. And for about $0<\mathrm{CR}<10$ and $0<\mathrm{PRD}<0.6$, the three-level quantization can be repeated to $10^{\text {th }}$ or more. The number of iteration depends on our particular application in which value of CR and PRD should be used to gain our favorite results.

\section{REFERENCES}

[1] J. R. Cox, F. M. Nolle, H.A. Fozzard, and G. C. Oliver. "AZTEC, a preprocessing program for real time ECG rhythm analysis " IEEE Trans. Biomed. Eng. Vol, BME15, pp. 128-129, 1968.

[2] J. P. Aberstein and W. J. Tompkins,"A new data reduction algorithm for real time ECG analysis" IEEE Trans. Biomed. Eng. Vol. BME-29, pp. 43-48, 1982.

[3] Z. Lu, D. Y. Kim, and W. A. Pearlman, "Wavelet compression of ECG signals by the set partitioning in hierarchical trees algorithm," IEEE Trans. Biomed. Eng., vol. 47, pp. 849-856, July 2000

[4] S. G. Miaou, H. L. Yen and C. L. Lin, "Wavelet-based ECG compression using dynamic vector quantization with tree codevectors in single codebook," IEEE Trans. Biomed. Eng., vol. 49, pp. 671-680, July 2002.

[5] S. G. Miaou and S. N. Chao, "Wavelet-based lossy-tolossless ECG compression in a unified vector quantization framework," IEEE Trans. Biomed. Eng., vol. 52, pp. 539543, March 2005.
[6] A. Al-Shroufa, M. Abo-Zahhad and Sabah M. Ahmedc, "A novel compression algorithm for electrocardiogram signals based on the linear prediction of the wavelet coefficients," Digital Signal Processing, Elsevier, vol. 13, pp. 604-622, October 2003.

[7] A. Alshamali and A.S. Al-Fahoum, "Comments on "An efficient coding algorithm for the compression of ECG signals using the wavelet transform," IEEE Trans. Biomed. Eng., vol. 50, pp. 1034-1037, August 2003.

[8] J. Chen, J. Ma, Y. Zhang and X. Shi, "ECG compression based on wavelet transform and Golomb coding," Electron.Lett., vol. 42, no. 6, pp. 322-324, March 2006

[9] R. Benzid, F. Marir and N. E. Bouguechal, "Electrocardiogram Compression Method Based on the Adaptive Wavelet Coefficients Quantization Combined to a Modified Two-Role Encoder," IEEE Signal Pro, Lett, vol. 14, pp. 373-376, June 2007.

[10] P. S. Hamilton, "Adaptive compression of the ambulatory electrocardiogram," Biomed. Inst. Technol., vol. 27, no. 1, pp. 56-63, Jan. 1993.

[11] A. Al-shrouf, M. Abo-Zahhad, S. M. Ahmed. " A novel compression algorithm for electrocardiogram signal based on the linear prediction of the wavelet coefficients " Digital Signal Processing, Vol.13, 2003, pp. 604-622.

[12] M. Blanco-Velasco, F. Cruz-Roldan, J. I. Godino-Llorente and K. E. Barner, "Wavelet Packets Feasibility Study for the Design of an ECG Compressor," IEEE Trans. Biomed. Eng., vol. 54, pp. 766-769, April 2007.

[13] J. M. Shapiro,"Embedded Image Coding Using Zero-Trees of wavelet Coefficients", IEEE Trans. On Signal Processing, vol. 41. NO. 12. pp. 3445-3462, 1993.

[14] Said A, Pearlman WA. A new, fast, and efficient image codec based on set partitioning in hierarchical tree. IEEE Trans. CSVT 1996;6(3):243-50.

[15] Gersho A, Gray RM. Vector Quantization and Signal Compression. New York: Kluwer Academic Press, 1992.

[16] Sang Joon Lee and Myoung ho Lee $30^{\text {th }}$ Annual International IEEE Conference Vancouver, British Columbia, Canada , August 20-24, 2008

[17] H. L. Chan, Y. C. Siao, S. W. Chen and S. F. Yu, "Wavelet-based ECG compression by bit-field preserving and running length encoding", Computer Methods and Prog. in Biomedicine, vol.90, pp.1-8, 2008.

[18] C. M. Fira and L. Goras, "An ECG signals Compression Method and its Validation using NNs", IEEE Trans Biomed. Eng, vol. 55, No. 4, pp. 1319-1326, 2008.

[19] H. Kim, R. F. Yazicioglu, P. Mercen, C. V. Hoog and H. J. Yoo, "ECG signal compression and classification with Quad Level Vector for ECG Holter system”, IEEE Trans Inf. Tech. in Biomed, vol.14, No.1, pp. 93100, 2010.

[20] C. S. Burrus. R. A. Gopinath. H. Guo, introduction to Wavelets and Wavelet Transforms, Prentice-Hall, 1997.

[21] S. G. Mallat,"A Theory of Multiresolution signal decompression; The Wavelet Representation", IEEE Trans. Image Processing, vol. 1, no. 2, pp. 205-220, April 1992.

[22] J. M. Shapiro,"Embedded Image Coding Using Zero-Trees of wavelet Coefficients", IEEE Trans. On Signal Processing, Vol. 41. NO. 12. pp. 3445-3462, 1993. 
[23] P. Wellig, Z. Cheng, M. Semling, and G. S. Moschytz, " Electromyogram Data Compression Using Signal-Tree and Modified Zero-Tree Wavelet Encoding ", Proceeding of the $20^{\text {th }}$ Annual International Conference of the IEEE Engineering in medicine and biology society, Vol. 20, No. 3 , $\mathrm{pp}$ 1303-1306,

1998

[24] L. M. Ang, H. N. Cheung, and K. Eshraghian, "EZW Algorithm Using Depth-First Representation of the Wavelet Zero-Tree", $5^{\text {th }}$ International Symposium on Signal Processing and its Applications, pp. 75-78, 1999.

[25] Ali Bilgin, Michael W. Marcellin, Maria I. Altbach," Compression of Electrocardiogram Signals Using JPEG2000 " , IEEE Transactions on Consumer Electronics, Vol. 49, No. 4, November, 2003, pp. 833-840.

[26] I. M. Rezazadeh. M. H.Moradi, A.M. Nasrabadi, "Implementing of SPIHT and subband Energy Compression (SEC) Method on Two-Dimensional ECG Compression: A Novel Approach". Engineering in medicine and biology, $27^{\text {th }}$ annual conference, IEEE, China, 2005.

[27] S. M. E Sahraeian and E. Fatemizadeh. "Wavelet-Based 2D ECG Data Compression Method Using SPIHT and VQ Coding ". IEEE Int. Conf on "Computer as a tool" . EUOROCON 2007

[28] Z. Lu, D. Y. Kim, and W. A. Pearlman, "Wavelet Compression of ECG signal by the Set Partitioning in Hierarchical Trees (SPIHT) algorithm" IEEE Transactions on Biomedical Engineering, Vol. 47, July 2000 , pp. 849856.

[29] Ranjeet Kumar, A. Kumar, Rajesh K. Pandey "Beta wavelet based ECG signal compression using lossless encoding with modified thresholding" Computers and Electrical Engineering (Elsevier 2012)
[30] S.K. Mukhopadhyay, S. Mitra, , M. Mitra "An ECG signal compression technique using ASCII character encoding" Measurement (Elsevier) 45, 2012, pp. 1651-1660

[31] Eddie B . L . Filho, Nuno M. M. Rodrigues, Eduardo A. B . da Silva, S'ergio M . M . d e Faria, Vitor M . M . da S ilva, and M urilo B. de Carvalh," ECG Signal Compression Based on Dc Equalization and Complexity Sorting" IEEE TRANSAC TIONS ON BIOMEDICAL ENGINEERING, VOL. 55, NO. 7, JULY 2008

[32] Jianhua Chen, Fuyan Wang, Yufeng Zhang, Xinling Shi "ECG compression using uniform scalar dead-zone quantization and conditional entropy coding" Medical Engineering \& Physics (Elsevier), 30-2008, pp. 523-530

[33] R. Benzid, A. Messaoudi, A. Boussaad "Constrained ECG compression algorithm using the block-based discrete cosine transform" Digital Signal Processing 18 (2008) 5664

[34] Jin Wang, Xiaomei Lin and Kebing Wu "ECG Data Compression Research Based on Wavelet Neural Network" 2010 International Conference on Computer, Mechatronics, Control and Electronic Engineering (CMCE)

[35] Hilton ML. Wavelet and Wavelet Packet compression of electrocardiograms. IEEE Transactions on Biomedical Engineering 1997;44(5):394-402.

[36] Djohan, A., Nguyen, T.Q., Tompkins, w. J., ECG compression using discrete symmetric wavelet transform, IEEE $17^{\text {th }}$ annual Conference, Engineering in Medicine and Biology Society, vol.1, pp. 167-168, 1997. 